\title{
Tregs: Where We Are and What Comes Next?
}

\author{
Hai Zhao, Xuelian Liao and Yan Kang* \\ Department of Critical Care Medicine, West China Hospital, Sichuan University, Chengdu, China
}

Regulatory $T$ cells are usually recognized as a specialized subset of $\mathrm{CD}^{+}{ }^{+} \mathrm{T}$ cells functioning in establishment and maintenance of immune tolerance. Meanwhile, there is emerging evidence that regulatory T cells (Tregs) are also present in various non-lymphoid tissues, and that they have unique phenotypes credited with activities distinct from regulatory function. Their development and function have been described in plenty of manuscripts in the past two decades. However, with the deepening of research in recent years, emerging evidence revealed some novel mechanisms about how Tregs exert their activities. First, we discuss the expanding family of regulatory lymphocytes briefly and then, try to interpret how fork-head box P3 (Foxp3), a master regulator of the regulatory

OPEN ACCESS

Edited by:

Shohei Hori,

RIKEN Center for Integrative Medical Sciences (IMS), Japan

Reviewed by:

Masahide Tone,

Cedars-Sinai Medical Center,

United States

Bin Li,

Shanghai Jiao Tong University School of Medicine, China

${ }^{*}$ Correspondence: Yan Kang 1052815877@qq.com

Specialty section:

This article was submitted to Immunological Tolerance and Regulation, a section of the journal Frontiers in Immunology

Received: 08 September 2017 Accepted: 02 November 2017 Published: 24 November 2017

Citation:

Zhao H, Liao X and Kang Y (2017) Tregs: Where We Are and What Comes Next?

Front. Immunol. 8:1578. doi: 10.3389/fimmu.2017.01578 pathway in the development and function of regulatory T cells, functions. Subsequently, another part of our focus is varieties of tissue Tregs. Next, we primarily discuss recent research on how Tregs work and their faceted functions in terms of soluble mediators, functional proteins, and inhibitory receptors. In particular, unless otherwise noted, the term "Treg" is used here to refer specially to the "CD4+CD25+Foxp3" regulatory cells.

Keywords: regulatory T cells, Foxp3, regulatory innate lymphoid cells, neuropilin-1, D-mannose, amphiregulin

\section{INTRODUCTION}

Human beings possess a Daedalian engineering capable of eradicating both invading pathogens, from viruses to parasitic worms, and distinguishing them from the host's own healthy tissue. Nonetheless, containment of this bloodbath is essential to preventing the host from injury due to overwhelming or misguided immune activation. Regulatory $\mathrm{T}$ cells (Tregs) act as the nucleus in enforcing immune tolerance $(1,2)$. They are mobilized as essential controller of varieties of immune responses-including allergy, autoimmunity, inflammation, and tumors immunity (3). Several present studies, additionally, have revealed a heterogeneous and multidimensional nature of tissue Tregs beyond suppressive functions. These newfound functions include helping hair follicles regeneration (4), preserving intestinal homeostasis and more importantly, participating in tissue repairing (5). Although Tregs have been reviewed extensively on all sides, most previous reviews focused on circulating subpopulation. An analysis of their novel recognized suppressive mechanisms and physical functions has not been reviewed recently.

Since their discovery in the late 1960s (6), Tregs have been extensively studied and been treated as a promising potential therapeutic tool. Determining how Tregs work is an important goal and have perplexed immunologists since they came into view. In earlier times, a variety of molecules are found to be involved in Treg-mediated suppressive activity, including cytotoxic T-lymphocyteassociated protein 4 (CTLA-4), IL-2, IL-10, TGF- $\beta$, IL-35, glucocorticoid-induced TNF receptor (GITR), lymphocyte-activation gene 3 (LAG3), granzyme B, adenosine, and cyclic AMP (cAMP). 
Recently, numerous studies have reported metabolic and genetic contributions, ranging from metabolic regulation estimates to mapping of immune-related genes.

Remarkably, Tregs are not alone (see Figure 1). At first, three main types of $\mathrm{CD}^{+}$regulatory cells have been firmly established: IL-10-producing $\operatorname{Tr} 1$ (type 1 regulatory T) cells, TGF- $\beta$-producing $\mathrm{CD} 4{ }^{+}$Th3 (T helper 3 ) cells, CD $4^{+} \mathrm{CD} 25^{+}$Foxp $3^{+} \mathrm{T}$ cells. Both $\mathrm{Tr} 1$ and Th3 lack fork-head box P3 (Foxp3) expression and several of cytokines were shown to account for their inhibition. Besides, the population of immunosuppressive cells also cover so-called myeloid-derived suppressor cells (MDSCs), regulatory B cells (Bregs), regulatory $\gamma \delta \mathrm{T}$ cell ( $\gamma \delta$-Tregs), immunosuppressive plasmocytes (ISPC), etc. Just very recently, a regulatory subset of ILCs (innate lymphoid cells) has also been identified (7).

Among these regulatory cells, $\mathrm{CD} 4^{+} \mathrm{CD} 25^{+} \mathrm{Foxp} 3^{+}$regulatory $\mathrm{T}$ cells are the most physiologically relevant due to their broad and indispensable roles. Hence, we focus on Tregs in this review and we should keep in mind that all regulatory cell members do not act in isolation but rather have myriad connections with each other to accomplish this biological play altogether. So we would not introduce heretofore the cutting edge pertinent to different phenotypes of regulatory cell members in detail. Herein we will introduce some recent bright research about Tregs suppressive mechanisms and try to explore their possible molecule targets.
It has been universally accepted that the physiological function of Treg is essential for the restraint of fatal autoimmune and inflammatory responses. There remains significant room and it is still necessary to identify unrecognized pathways regulating Treg development and function. Similarly, we should also keep in mind that relevant research cannot be considered independently. Rather, they interact to make up an elaborate, sophisticated manipulation of the immune system.

\section{Foxp3 AND Tregs}

The transcription factor Foxp3 is critically important for the development and function of Tregs (8). Foxp3 not only can keep the cells on right developmental tracks toward a suppressive phenotype, but also seems to be a prerequisite to for stabilizing the Treg lineage (9). Furthermore, loss of Foxp3 expression over time impairs the suppressive activity of Tregs $(10,11)$.

The genomic region of the Foxp3 locus has several conserved noncoding sequences, designated as CNS 0-3. Each sequence gets involved in different signaling pathways respectively. CNS0 represents a role in initiating Treg-SE (specific super-enhancers) activation to induce Foxp3 expression (12). Present findings also revealed that myeloid/lymphoid or mixed-lineage leukemia 4-AT-rich sequence-binding protein-1-CNS0 region complex

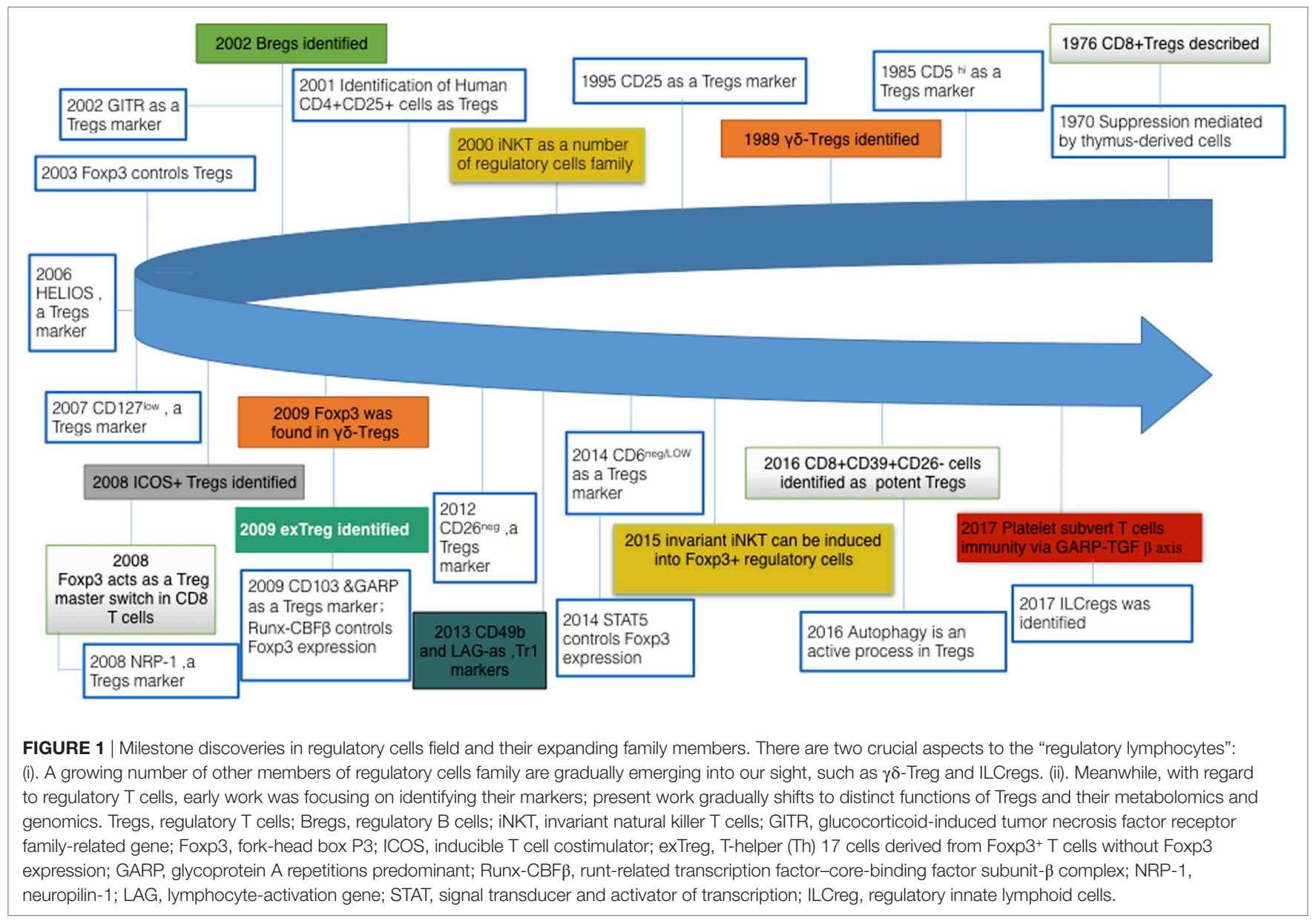


promotes looping of Foxp3 promoter (13). CNS1 contains binding sites for the nuclear factor of activated $\mathrm{T}$ cells and the activator protein 1 , which is indispensable to TGF- $\beta$ signaling mechanisms (14). Additionally, CNS1 is critical for TGF- $\beta$-induced Foxp3 induction in peripheral CD4+ T cells but not in thymocytes (15). CNS2, activated by TCR expression and interleukin-2, has varieties of transcription factor binding sites such as cyclic adenosine monophosphate response element-binding protein, signal transducer and activator of transcription (STAT5), and runt-related transcription factor (RUNX) $(16,17)$. Specially, RUNX1-CBF $\beta$ complex $\beta$ binding to CNS2 is crucial for sustaining a high and stable level of Foxp3 expression in Treg cells (18). Last in sequence but not least in importance, CNS3 acts like an essential element for Foxp3 induction during thymic and peripheral Treg differentiation by recruiting c-Rel and other transcription factors (19). Summarize, expression of Foxp3 alone is not sufficient for conferring and maintaining Treg cell function and phenotype. Foxp3 can be regarded as one of large transcriptional complexes, which contain some other transcriptional factors. For the interior, subunits of Foxp3 can bind different transcriptional factor to achieve development and functions of Treg.

Though Foxp3 acts as a master regulator of the suppressive pathway in the development and function of Treg, Foxp3 is not necessary for survival of Treg precursors (9). In addition, Foxp3 is not just for Tregs alone since it can be expressed in activated non-suppressive $\mathrm{CD}^{+} \mathrm{CD} 25^{-}$Tregs (20). More specifically, $\mathrm{T}$ cells posing the Treg-cell specific epigenetic changes are not completely overlap with those expressing Foxp3. To fully understand the relationship among CD25, Foxp3 and Treg epigenome, we refer readers to a comprehensive review on identity of Treg in Ref. (21).

\section{TISSUE Tregs}

It is becoming increasingly appreciated that Tregs accumulated in various nonlymphoid tissues are important parts of immune system. Tissue Tregs have unique phenotypes, different TCR repertoires, distinct functions. Identification of nonlymphoid tissues Foxp $3^{+} \mathrm{CD}^{+}$regulatory $\mathrm{T}$ cells fuels the notion that human immune system possesses a second critical function: maintaining organismal homeostasis. In this part, we will discuss tissue Tregs in four parts of the body-visceral adipose tissue (VAT), skeletal muscle, mucosal interface and hair follicle.

Regulatory $\mathrm{T}$ cell in VAT (VAT-Tregs, also known as "Fat Tregs"), as one of the well-characterized examples of tissue Tregs, seem to retain more strong suppressive ability since transcriptional level of IL-10 is $10^{2}$-fold higher than that in lymph nodes (22). Meanwhile, VAT-Tregs display elevated CCR1, CCR2, CCR9, CXCL10 and low CXCR3 expression which is induced by PPAR $\gamma$ (peroxisome proliferator-activated receptor- $\gamma$ ) (23). They are abundant in VAT of lean mice, and instead, they would dramatically decreased in insulin-resistant animal models of obesity (22). Their development was largely due to effects of PPAR $\gamma$, which is a master regulator of the accumulation, phenotypes and functions of adipose tissue Treg cells (23). Additionally, the transcriptional regulator basic leucine zipper transcriptional factor ATF-like, interferon regulatory factor 4, together with IL-33 and its receptor, suppression of tumorigenicity 2 (ST2; also known as IL-1RL1) play an indispensable role in VAT-Tregs differentiation (24). VAT-Tregs have been suggested to get involved in some metabolic disorders such as atherosclerosis (25), obesity (26), and diabetes (27), strengthening this type of tissue Tregs as a promising target for therapeutic interventions.

Muscle-resident Tregs was first identified in genetically dystrophic mice in 2013 (28). They display enhanced expression of IL-10, Granzyme B, plate-derived growth factor, amphiregulin, CCR1, CCR2 and of particular importance is ST2 (IL-33 receptor). In addition, muscle-resident Tregs are supposed to be exported from the thymus since they are accompanied with high levels of Helios and Neuropilin (28). In the synergic sequence of events underlying muscle repair, muscle-resident Tregs adequately contribute to this process and come into the limelight. A more recent research has revealed the close correction between muscle-resident Tregs and muscle recovery from injury (29). The authors first identified that muscle-resident Tregs were reduced in aged mice who were characterized by delayed or impaired muscle recovery. Then they found administration of IL-33 restored the Treg population and enhanced regeneration, opening a new therapeutic avenue for poor wound healing to explore. However, the role of amphiregulin, which is considered to directly modulate muscle homeostasis and regeneration $(5,28)$, in the research seems unclear. Moreover, how muscle-resident Tregs capture damage signal and how they subsequently export from the thymus awaits elucidation.

A large fraction of Tregs accumulate at mucosal interfaces, especially the lamina propria of colon. Intestinal microenvironment provides the venue where commensal microbes accrete with immune cells. Therefore, the TCR repertoire of colonic Tregs is distinct from that of colonic effector T cells or Tregs in other tissue sites. Intestinal Tregs exhibit increased expression of IL-10 and TGF- $\beta$, which is in accordance with the unique array of antigens they are exposed to (30). Just like muscle-resident Tregs, more than half of the intestinal Tregs display ST2. IL-33 not only facilitates intestinal Tregs differentiation but also promotes their accumulation in inflamed tissues (31). Additionally, a significant proportion of intestinal Tregs coexpress the transcription factor GATA-binding protein 3 (GATA3) which regulates ST2 expression $(32,33)$. Herein, we did like to spend a small amount of space to compare intestinal Tregs with ILCregs. ILCregs, namely regulatory innate lymphoid cells, were found to exist in mouse and human intestines (7). In stark contrast with intestinal Tregs and other innate lymphoid cells, ILCregs lack typical transcription factors such as Foxp3, GATA3, and retinoic acid receptorrelated orphan receptor- $\gamma$ t. They suppress the functions of innate lymphoid type 1 cells and innate lymphoid type 2 cells via IL-10 and TGF- $\beta$ mainly. Though exploration of gut-associated regulatory cells in humans is only beginning, the interactions between immune system and them promise to be particularly fruitful areas of future study.

The presence of tissue Tregs in diverse nonlymphoid organs in both mice and humans has attracted a great deal of attention over the past few years. VAT-, skeletal muscle-, and gut-associated tissue Tregs are at the cutting edge in this field. However, it is also important to deepen our understanding of Tregs in several 
other regions, including central nervous system, hair follicle, and cardiac muscle, especially their specialized roles of each in regulating local immune responses and their tissue-specific functions.

Given that Tregs are potent mediators of the immune response for the maintenance of dominant self tolerance and immune homeostasis, there is considerable interest in determining their mechanisms of action. The mechanism by which Tregs exert their function has been pursued relentlessly for decades. It has become apparent that Tregs have evolved a wide range of mechanisms by which to maintain its role in immune responses. These mechanisms can be classified into categories of: (i) suppressive cytokines (IL-10, TGF- $\beta$, IL-35, etc.); (ii) metabolic disruption (cAMP, CD39, CD73, etc.); (iii) modulation of antigen presenting cells maturation or function; and (iv) suppression by cytolysis. But are there more undiscovered mechanisms and/or molecules that mediate Tregs function? It is a matter of debate in the field and we should be aware that it has no end in the near future.

\section{SOLUBLE MEDIATORS DERIVED FROM Treg}

\section{Cyclic AMP}

Treg contains a high concentration of cAMP, while effector T cell has non-detectable cAMP loads (34). But no consensus has been reached as to which exquisite mechanism are closely related to cAMP. There are presently two different theories. In one scenario, CD39 and CD73, cell surface ectoenzymes that convert ATP/ADP to adenosine in synergy, are highly expressed on Treg (35). As a result, high quantities of adenosine are released into the extracellular space. Then this small molecule activates A2a receptors on effector T cells and increases intracellular cAMP to inhibit TCRmediated signaling by preventing zeta-chain-associated protein kinase 70 (ZAP70) phosphorylation and activator protein-1 activation (36). The subsequently decreased TCR signaling leads to impaired CD25 expression and IL-2 production which are detrimental to effector $\mathrm{T}$ cells proliferation and activation.

Besides, Tregs themselves carry innumerable cAMP and can directly delivery this small molecule to effector $\mathrm{T}$ cells via gap junction to exert suppressive function as mentioned. This communication type was demonstrated by inserting calcein which is the unique permeable dye for gap junction $(37,38)$. There are two points worthy of our attention.

First, Foxp3 can strongly downregulate $P d e 3 b$ locus while phosphor-diesterase $3 b$ hydrolyzes cAMP and cGMP (9). Second, Foxp3 additionally suppresses expression of miR-142-3p which is a potent inhibitor of adenylyl cyclase 9 (AC9) while AC9 retains the ability to generate cAMP (see Figure 2) (39). Consequently, Tregs contain comparatively high levels of AC9 and cAMP, leading to the suppression of effector T cells and antigen-presenting cell (APC) after delivering cAMP via gap functional intercellular communication (GJIC). To be specific, GJIC has been emphasized as a novel pathway for Treg-mediated suppression. Kuczma et al. showed that deviant expression of connexin 43 (an important element of gap junction) impairs suppressive function of Tregs evidently (40). Further analyses revealed that both connexin43 and its analog alpha-connexin carboxyl-terminal peptide 1 can enhance gap junction aggregation (41). Hence, we have adequate reason to believe that all these involved will show promising application to regulating immune homeostasis.

\section{TGF- $\beta$}

TGF- $\beta$, namely transforming growth factor- $\beta$, is usually regarded as one inhibitory cytokine. Th9, Th17, and Tregs all require this cytokine for their development though they still need additional cytokine signals for their eventual fates, respectively (46). After activation via TCR, Foxp $3^{+}$T cells express glycoprotein A repetitions predominant (GARP) which increases latent TGF- $\beta$ activation. GARP ${ }^{-/-}$Tregs can still secrete latent TGF- $\beta$ which does not have biologic activity. The source of activated TGF- $\beta$ was largely the GARP/latent TGF- $\beta$ complex instead of only latent TGF- $\beta$. Notably, Helios, but not FoxP3,
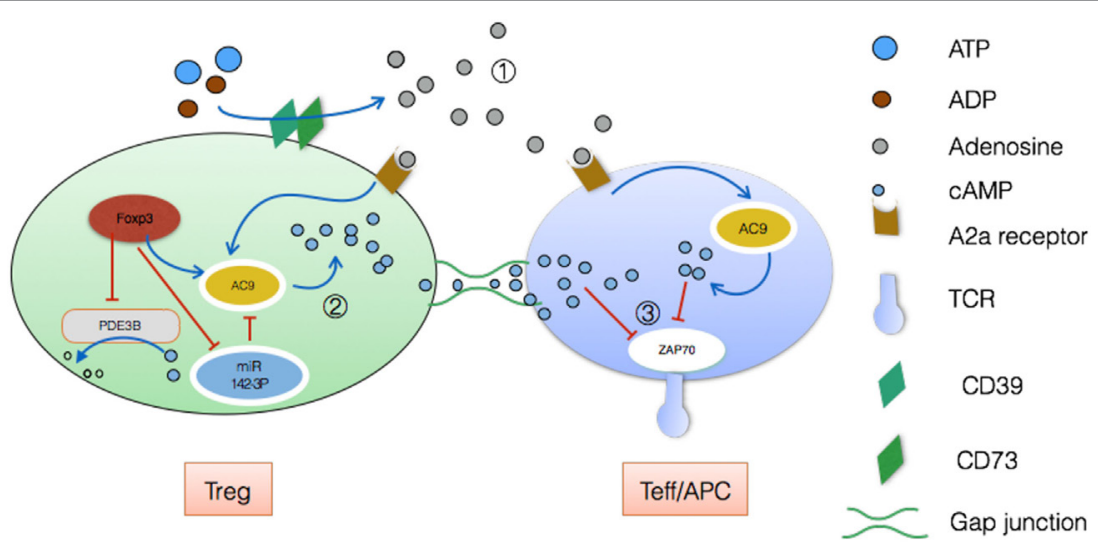

FIGURE 2 | Treg-mediated suppressive function via cyclic AMP (CAMP). (1) Through expression of the ectoenzymes CD39 and CD73, Treg drives the accumulation of adenosine extracellularly, which disrupts Teff metabolism, leading to anergy. During this process, adenosine activities high-affinity A2a receptors, with a result of plenty of cAMP by means of adenylyl cyclase 9 (42). (2) On the other hand, cAMP pool in Treg can be poured into Teff/APC by means of GJIC (43). Connexin43 plays an irreplaceable role in this delivery (44). (3) Finally, accumulative CAMP inhibits TCR-mediated signaling by preventing zeta-chain-associated protein kinase 70 (ZAP70) phosphorylation. This decreased TCR signaling leads to impaired Teff/APC activation and proliferation eventually (45). 
dominates the expression of the GARP/latent TGF- $\beta$ on activated human Treg (47). Considering its important role in activating latent TGF- $\beta$, GARP may represent an additional target to inhibit Treg suppression in cancer or augment suppression in autoimmunity (48).

D-mannose, a C-2 epimer of glucose, widely exists in a free state in some plant peel such as citrus skin. According to the latest knowledge, $\mathrm{D}$-mannose can induce naive $\mathrm{T}$ cells differentiation toward Tregs in a dose-dependent manner (0-50 mM) by promoting TGF- $\beta$ activation (49). After oral administration of D-mannose into models of autoimmune diabetes and airway inflammation, the researchers found immune responses of the objects showed an immunoregulatory phenotype and subsequent tolerance. Instead, inhibition of TGF- $\beta$ signaling can counterbalance the D-mannose-induced Treg generation. More importantly, long-term supplementation with $\mathrm{D}$-mannose would produce no adverse consequence. Combined with its easy acquisition, D-mannose-involved immune responses have particular implications for a similar clinical therapy for some frequently occurring diseases such as type 1 diabetes in humans.

As mentioned before, Tregs exhibit functional and phenotypic heterogeneity. Konkel et al. showed that TGF- $\beta$ signals limit Treg suppression of Th1-responses but are key for Treg function in the colon (50). They revealed a series of previously unrecognized role of TGF- $\beta$, including maintaining CD103 expression, boosting G-protein coupled receptor 15 (a colon-specific trafficking molecule) expression and inhibiting GPR174 (a G-protein-coupled receptor for lyso-phosphatidylserine) expression. The study has dramatically broadened our understanding of TGF- $\beta$ in immune responses.

Summarily, some early in vitro studies indicated TGF- $\beta$ was not essential prerequisite for the function of naturally occurring Tregs (51) but ensuing research gradually overturned this antecedent conclusion. Especially, relationships between TGF- $\beta$ and IL-2, GARP, Gfi-1(growth factor independent 1) still need further investigations (see Figure 3). For a more comprehensive description of how TGF- $\beta$ participating in Tregs-mediated suppression, especially in the interplay between immune cells and the microbiota in the gastrointestinal tract, we recommend a recent review (52).

\section{Neuropilin-1}

Expression of Neuropilin-1 on human Tregs has been a contentious subject $(60,61)$. In the past few years, awareness of Neuropilin-1, known as a coreceptor for both semaphorin family members and vascular endothelial growth factor, has grown, as has interest in its potential therapeutic role in promoting antitumor immunity. In contrast to the silent expression of healthy donor peripheral Tregs, Neuropilin-1 is expressed by approximately $90 \%$ of tumor infiltrating Tregs in cancer patients (62) and increased percentage of human Neuropilin- $1^{+}$intratumoral Tregs correlates with poor prognosis. Being here, we highlight a recent study by OveracreDelgoffe et al. who proved the key role of Neuropilin-1 in Treg function fragility (63). They found Treg-restricted deletion of Neuropilin-1 facilitates its IFN- $\gamma$ production, which extends previous data that a small subsets of Tregs can generate IFN- $\gamma$ (64). Very importantly, Nrp1 deficiency in Tregs would not induce any autoimmune or inflammatory disease of host, indicating that

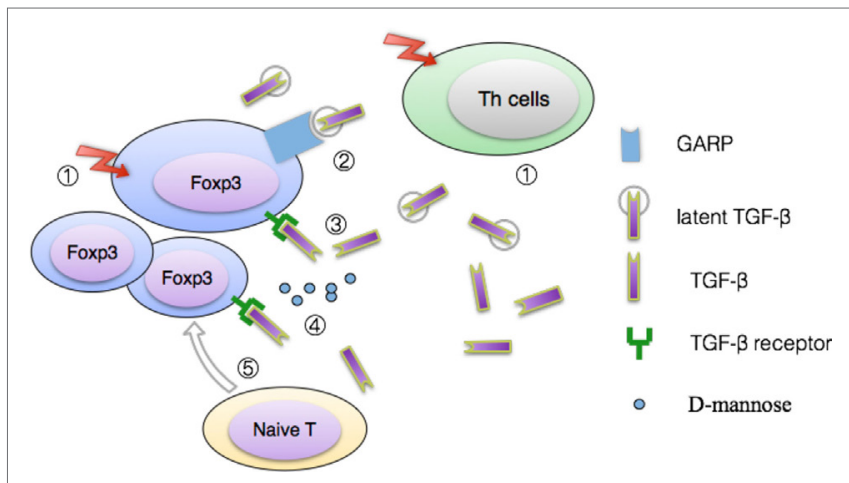

FIGURE 3 | Model for TGF- $\beta$ production by Treg. (1) The latent form of TGF- $\beta$ can be released from both activated Tregs and T helper cells $(53,54)$. Inside latent TGF- $\beta$ form, latency-associated peptide (LAP) is bound tightly to active TGF- $\beta$, acting as a shield which separate active TGF- $\beta$ from its receptor. (2) Glycoprotein A repetitions predominant protein (GARP), a kind of transmembrane anchor to keep latent TGF- $\beta$ cling to the cell surface, is a cell surface receptor on activated Tregs, platelets, but negligible expressed on Th clones $(55,56)$. Combined with LAP and mature TGF- $\beta$, GARP represents the third part of a muti-protein complex in activated Tregs. Or, GARP can be regarded as a covalent receptor for latent TGF- $\beta$ in active Tregs.

Subsequently, association of TGF- $\beta$ with GARP induces activation of the latent complex via integrin $\alpha_{v} \beta_{6}$ or integrin $\alpha_{v} \beta_{8}$ (57). (3) Active TGF- $\beta$ interacts with its specific receptors to induce cellular responses. (4) Recent research disclosed that D-mannosem can upregulate levels of integrin $a_{v} b_{8}$ and reactive oxygen species generated by increased fatty acid oxidation, which facilitates activation of the latent TGF- $\beta$ (49). (5 In synergy with IL-2, TGF- $\beta$ promotes the conversion of naive CD4+ T cells toward Tregs by upregulating expression of Foxp3 $(58,59)$.

Neuropilin-1 is dispensable for prevention of autoimmunity or maintenance of immune homeostasis.

Regulatory $\mathrm{T}$ cells, as a major barrier to effective antitumor immunity, have multifaceted roles in promoting tumor development through immune escape and angiogenesis. Though it is not necessary for immune homeostasis, Neuropilin-1 is yet indispensable for Tregs to limit antitumor responses (65). In the tumor context, Treg-restricted Neuropilin-1 deletion can revert antitumor responses based on more than one pathways: first, Neuropilin-1 directly enforces Treg stability and function in the tumor microenvironment. Neuropilin-1 ablation significantly impairs stability and suppressive activity of Tregs via inhibiting Akt functions. Second, Neuropilin-1-deficient Tregs show proinflammatory phenotype-secreting IFN- $\gamma$-instead. IFN $\gamma$ is an important activator of macrophages and inducer of MHC II molecule expression. It can limit Treg expansion (66) and drives Treg fragility to promote antitumor immunity. Recently, it was observed that IFN- $\gamma$ helps to prevent relapse by keeping the tumor in an ischemic state (67). Finally, the authors demonstrated that Neuropilin-1-deficient Tregs also negatively impact the function of surrounding intratumoral normal Tregs.

This milestone discovery makes Neuropilin-1 one potential therapeutic target, which could restrain Treg-mediated antitumor effects without inducing autoimmunity. As high-level Tregs in intratumoral setting are key players in tumor escaping and angiogenesis, selectively targeting intratumoral Tregs while maintaining peripheral tolerance is of vital significance. If we can 
turn the powerful foe into mighty friend, Treg will become one advanced weapon against cancer and other diseases.

\section{Amphiregulin}

As an activating ligand of the epidermal growth factor receptor, amphiregulin is expressed by multiple cell types in a variety of inflammatory setting including group 2 innate lymphoid cells, basophils, mast cells and Tregs. A previously unrecognized population of Tregs with amphiregulin-expressing was found accumulating in injured skeletal muscle (28) and inflamed colon of mice (31). Recently, Arpaia et al. have showed that amphiregulindeficient in tissue Tregs induces severe tissue damage but without impaired suppressive function (5). They demonstrated that Tregs have a major direct role in tissue repair which is invoked by separable cues. For years, as we know, congenital deficiency in Tregs causes fatal autoimmunity in so called scurfy mice (68), and IPEX syndrome in humans (69). The etiology of these disorders has mostly been attributed to the failure of Tregs to exert suppressive function. However, this conclusion needs to be fresh and up-to-date, with the recognition of Tregs' non-redundant role in tissue repair. Besides, these amphiregulin-expressing Tregs also display a characteristic gene expression and a specific TCR repertoire in stark contrast with that of splenic Tregs. Amphiregulin production in tissue Tregs is elicited via IL-33 and IL-18 rather than TCR signaling. That amphiregulin expression is dispensable for their suppressive function reinforces the heterogeneity of Treg compartments. Heterogeneous subpopulations of Tregs are possibly armed with diverse functions, and Tregs are not merely immune component.

Although amphiregulin is dispensable for Treg suppressor function, it does not detract amphiregulin from being a promising clinical biomarker and therapeutic target. For example, increased amphiregulin levels have been found in nonneoplastic diseases, including inflammatory diseases $(70,71)$ and autoimmune diseases $(72,73)$. Furthermore, amphiregulin is involved in cancer progression and has become the focus of several basic, translational, and clinical investigations (74-76). A growing number of studies support the concept that amphiregulin is indispensable for tissue integrity, and ultimately to abstain tumor development. In this regard, to better understand its upstream regulation and its interaction with other signaling molecules still need to be demonstrated. Admittedly, the mechanisms regulating amphiregulin expression, the relationship between amphiregulin and IL-33, and the exact role of amphiregulin in heterogeneous Treg subpopulations remains elusive. Targeting specifically the crosstalk between immune and epithelial cell via amphiregulin still holds promise for the development of therapeutics to combat non-neoplastic diseases and cancer.

\section{Interleukin-34}

Interleukin-34, a newcomer of human interleukin family, first described in 2008, was found to be crucial in cell proliferation, differentiation, inflammation, angiogenesis, migration and adhesion (77). It has another two distinct receptors, namely PTP- $\zeta$ (the receptor-type protein-tyrosine phosphatase zeta) and CD138 in addition to the earlier demonstrated colony-stimulating factor-1 receptor (CSF-1R). The affinity of IL-34-CSF-1R binding is higher than CSF-1-CSF-1R binding since IL-34 recruits two domains of CSF-1R, while CSF-1 recruits only one (78).

Bézie et al. proved IL-34 retains immunosuppressive properties and they identified IL-34 as a tolerogenic cytokine with miscellaneous physiological functions (79). They first observed that IL-34 is specifically expressed by $\mathrm{CD} 4^{+} \mathrm{CD} 45 \mathrm{RC}^{\text {lo }}$ Foxp $3^{+}$ and $\mathrm{CD}^{+}{ }^{+} \mathrm{CD} 45 \mathrm{RC}^{\text {lo }}$ Foxp $3^{+}$Tregs. In more detail, nearly half of the $\mathrm{CD}^{+}{ }^{+}$Foxp $3^{+}$Tregs express IL-34, indicating its specific role in Treg function. Still other studies found diverse functions of IL-34 such as inducing proinflammatory cytokines (80), driving regulatory macrophages generation (81).

Interleukin-34 is involved in the development of a series of diseases such as rheumatoid arthritis $(82,83)$, inflammatory bowel disease $(84)$ or neoplastic disorders $(85,86)$. The biology and underlying mechanism of this interleukin remain debatable today and its relation with Tregs still awaits further elucidated. What we have known is far from enough, but we still have faith in its potential key role in immune regulation.

\section{Interleukin-35}

Interleukin-35, a newly discovered member of IL-12 family, is the most important cytokine with anti-inflammatory properties besides TGF- $\beta$ and IL-10. IL-12 family, including IL-12, IL-23, IL-27, and IL-35, are composed by two of the following five subunits-p19, p28, p35, p40, and Epstein-Barr virus-induced gene 3. To be specific, two chains forming the heterodimeric IL-35 are the $\alpha$-chain (p35, shared with IL-12) and $\beta$-chain (also a component of IL-27), both of which are highly expressed by Tregs other than effector cells or APCs (87).

While IL-12, IL-23, and IL-27 are proinflammatory immune cytokines, IL-35 is a purely immunosuppressive cytokine. For the moment at least, Tregs are thought to be the main source of IL-35 and this potent cytokine is indispensable to their maximal suppressive capacity (88). Of note, not only is IL-35 in a position to directly suppress effector $\mathrm{T}$ cell response, it is also able to induce iTr35 cells generation (89). After being secreted by Tregs, IL-35 subsequently acts on its target cells by binding to its receptor, which is composed of IL-12 22 and gp130. Once combined, the signal will be transducted through STAT1 and STAT4, which eventually results in a feedback loop promoting IL-35 expression (87) (see Figure 4). In addition, IL-35 has been well demonstrated to enhance the proliferation of nTregs as opposed to IL-12 and IL-27(90).

Recently, emerging studies of IL-35 involvement in human diseases have been reported, including inflammatory disease, autoimmune diseases, neoplastic disease. In particular, Turnis et al. have shown that Tregs-derived IL-35 is enriched in tumors and promotes exhaustion of effector $\mathrm{T}$ cells in this microenvironment (91). They speculated that IL-35 becomes a more prominently utilized suppressive mechanism in cancer especially. There is no doubt that IL-35 exerts an important role in the pathogenesis and development of multiple disease although its accurate role remains somewhat controversial. Indeed, studies focusing on IL-35 have gradually changed from animal models into human studies, suggesting a promising therapeutic target of IL-35. The primary challenge we face is the difficulty to 


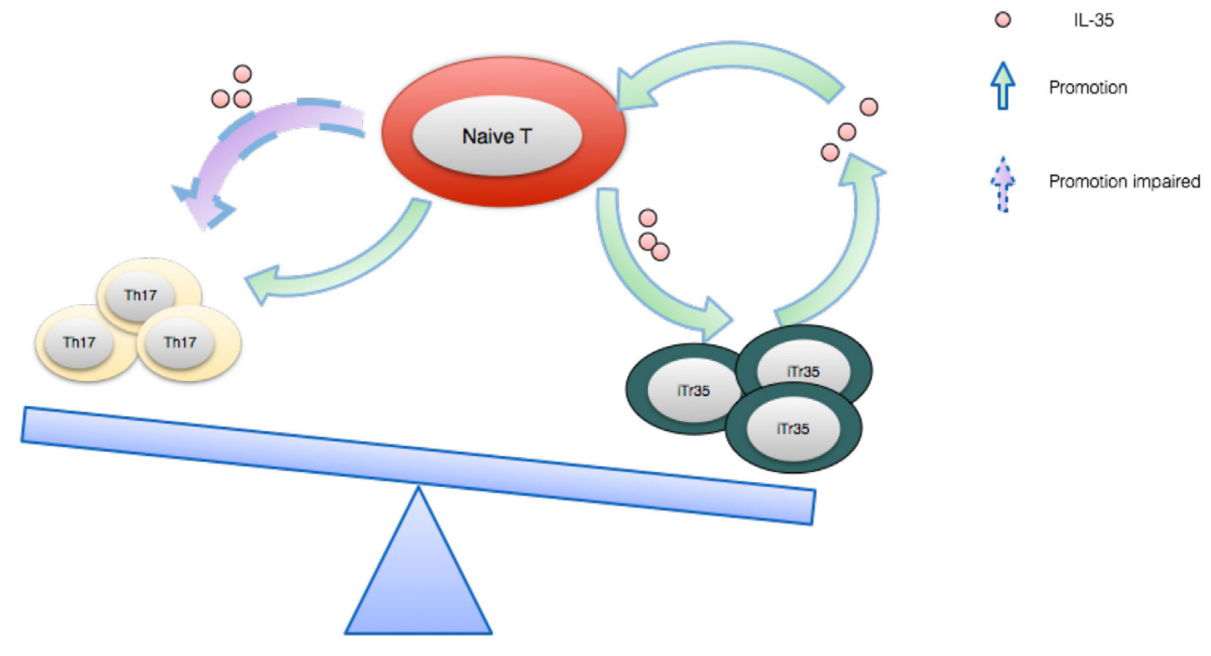

FIGURE 4 | The IL-35 expression feedback loop and how it balances Th17 cells and iTr35. IL-35 induces naive T cells to differentiate toward regulatory iTr35 cells while the latter further secrete higher concentration of IL-35, forming a positive feedback cycle. Conversely, IL-35 generates a negative effect on the differentiation and function of Th17 cells.

produce IL-35. How can similar IL-12 family members produce diverse functions? How do these subunits exactly work? If we pair p35 with p28 or p19, will the compound present proinflammatory or anti-inflammatory function? Furthermore, as a newly recognized inhibitory molecule, what we have known may be just a tip of the iceberg. In addition to its advantageous effects, we should meanwhile take potential deleterious impairment on board.

It is worth mentioning that the suppressive activity of IL-35 is not confined to $\mathrm{CD}^{+}$Tregs. A subpopulation of $\mathrm{CD}^{+}$Tregs was also identified to inhibit the proliferation of effector $\mathrm{T}$ cells in a similar IL-35-dependent manner (92).

\section{EFFECTS OF ECTOENZYMES AND INHIBITORY RECEPTORS ON Treg SUPPRESSION}

\section{CD39 and CD73}

CD39 and CD73 play strategic roles in transformation from ATP-induced proinflammatory mileu to adenosine-induced anti-inflammatory mileu. About $80 \%$ of Foxp $3^{+}$Tregs retain a high concentration of these two ectonucleotidases (93). And more, Tregs also secrete exosomes containing CD39 and CD73 and these exosomes have been found to suppress effector $\mathrm{T}$ cells proliferation (94).

Adenosine generated by CD39 and CD73 on Tregs can bind the $\mathrm{A}_{2 \mathrm{~A}}$ adenosine receptors on effector $\mathrm{T}$ cells and enhance intracellular cAMP levels to suppress their function. Hence, they have been increasingly used as functional markers of Tregs. Notably, CD39 is regarded as the rate-limiting component of this ectoenzymatic chain. Effects of them upon adenosinergic loops comprise a component of the suppressive machinery of Tregs. One recent review by Cekic and Linden (93) has elaborated this labyrinth among them and again we will not reiterate them here.
Herein we highlight some recent advance in understanding of CD39 and CD73.

Indeed, there exists a substantial obstacle to the understanding of immune regulation, largely because the major self-antigens recognized by Tregs have far remained elusive. In addition to being an ATP hydrolase, Gruenbacher et al. recently proved CD39 on V $\gamma 9 \mathrm{~V} \delta 2 \mathrm{~T}$ cells dephosphorylates and thus desensitizing phosphoantigens-associated responses (95). With the boom of chimeric antigen receptor $\mathrm{T}$ cell therapy, identification of Treg-associated antigen appears to be particularly important. Hydrolyzing specific antigens would be un previous unrecognized pathway Tregs functions, at least for V $\gamma 9 \mathrm{~V} \delta 2 \mathrm{~T}$ cells. Recently, Leonard et al. also identified two Treg clones recognized distinct non-overlapping MHC-class-II-restricted peptides derived from transient receptor potential cation channel subfamily $\mathrm{M}$ member 8 -channel-associated factor 3 (96). These bright works could be exploited as a potent strategy for identifying the Tregs antigen relevant to human autoimmunity.

Notably, in contrast to murine Tregs, CD73 is predominantly expressed intracellularly in human Tregs. It has been reported that in humans, only $1 \%-5 \%$ of circulating FOXP $3^{+} \mathrm{CD} 4^{+} \mathrm{T}$ cells expresses CD73 while its surface expression on human Tregs can be induced upon activation (97). Also, the role of CD73 on Tregs is confirmed since inhibition of it impairs their suppressive capacity. Indeed, besides its enzymatic function, CD73 can also be regarded as one adhesive molecule that can regulate cell interaction with extracellular matrix components to mediate cancer invasive and metastatic properties. Several studies revealing the relationship between CD73 and clinical prognosis have sprung up (98-103). Further, anti-CD73 therapy alone (104) or combined with other inhibitory molecules (105) have produced inspiring benefits in preclinical models. Admittedly, these advancements may reflect the relationship between CD73 and tumor microenvironment rather than Tregs alone. But they are still instructive for us to study Tregs in depth. With the advent of Generation 
3 immunoncology, molecule target ranks enormous position and the future of CD73-targeted therapy holds even brilliant prospects.

\section{CTLA-4}

Cytotoxic T-lymphocyte-associated antigen 4 (CD152) is regarded as a "leader" checkpoint inhibitor since it terminates potentially autoreactive $\mathrm{T}$ cells at earlier stage in contrast to another star-programmed cell death 1 (PD-1). The CTLA-4 level of conventional $\mathrm{T}$ cells will rise once they are activated yet it is constitutively and especially expressed on Tregs in the resting immune system. It is well demonstrated that CTLA-4 gets involved in crucial function of Tregs given that CTLA-4 binds B7 with a higher affinity than CD28 (106). This competition for ligand binding sets up a potent immuno-modulation targetCTLA-4 blockade induced an increased availability of ligands for CD28 binding and the reverse is also true. Competition with CD28 on T cells for B7 signaling, negatively regulating APCs via B7 (107) and Trans-endocytosis of B7 (108) constitute the basic biology of CTLA-4. Many molecules get involved in CTLA-4-mediated downstream signaling pathway in $\mathrm{T}$ cells,

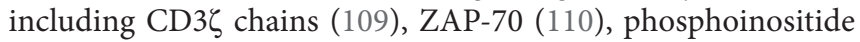
3-kinase (111), AKT (protein kinase B) (112) and protein kinase $\mathrm{C}$ isoform (113), etc. However, none of these theories has won a landslide victory and the debate over this molecule will last in the near future.

Since Ctla4 is a target gene of Foxp3, this leads to the concept that CTLA-4 might engage in directing the homeostasis and function of Tregs. Firstly, CTLA- 4 in Tregs can act as an intrinsic brake on their proliferation. Deletion of CTLA-4 resulted in enhanced Tregs multiplication (114). Further, injecting mice with a CTLA-4 specific blocking antibody also rapidly induce Tregs proliferation (115), fueling the original observation. By comparison, loss of IL-10 expression of Tregs fails to induce systemic autoimmunity, indicating that systemic immune homeostasis has tight association with the expression of CTLA-4 rather than IL-10 (116). In contrast, blockade of B7 molecules with CTLA-4-Ig remarkably decreases the number of memory Tregs which exhibit stronger suppressive function (117). This manipulation, however, induces negligible effect on the naive Treg subpopulation (117). Summarily, loss of CTLA-4 increases Tregs numbers while loss of CD28 results in markedly decreased Tregs numbers. Second, CTLA-4 plays a key role in Tregs function, at least in some settings. Loss of CTLA- 4 in Tregs can lead to impaired suppressive activity of Tregs (118) and aberrant function of conventional T cells (119). Recent data have proved CTLA-4 expressed by Tregs can prevent inflammatory tissue attack in arthritis context (120). Very low dose of IL-2 (less than $5 \mathrm{IU} / \mathrm{ml}$ ) was also found to enhance Tregs function in a CTLA-4-dependent manner (121). It is archived via selective phosphorylation of STAT-5 in Tregs rather than other cell lineages. But there appeared a different voice meanwhile-blocking the function of Treg with CTLA-4 antibodies in vitro fail to produce impaired Tregs suppression (122). This embarrassment was mainly due to CTLA-4 sharing communal ligands with B7. The ultimate way-out to this solution maybe lies in ideally interrupting CTLA-4 pathway while leaving CD28 pathway intact.
In a surprising twist, controversies over CTLA-4 of Tregs do not affect their clinical application. It is an emerging diagnostic marker and therapeutic target for human diseases at present. For example, in early onset breast cancer, immunohistochemistry expression of CTLA-4 was investigated and its mean percentage value in intratumoral lymphocytes reached $8.24 \%$ (123). There is also a significant correlation between CTLA-4 expression and overall survival in different cancer cases (124). More importantly, CTLA-4 has been extensively studied for immunotherapy besides PD-1. Monoclonal antibodies targeting CTLA-4 (e.g., ipilimumab, tremelimumab) have emerged as potent weapons against cancer and show great promise in treating a broad range of diverse tumor types $(125,126)$. Anti-PD-1 and anti-CTLA-4 have complementary activities and the combination of PD-1 and CTLA- 4 blockades brought about more benefits than either agent alone $(127,128)$.

Considering the sustained expression on all Tregs, it seems tenable to consider CTLA- 4 as a core suppressive molecule. This hypothesis is fueled especially in the burgeoning trend of low dose IL-2 therapy. As discussed previously, CTLA-4-mediated suppression is a significant pathway by which low dose IL-2 confers enhanced suppressive potential to Tregs (121). We can speculate whether CTLA-4 is the priority option and whether CTLA-4 alone is enough for Tregs function. Admittedly, a more detailed framework is still required in order to clarify this controversial but non-negligible player.

\section{PD-1}

The coinhibitory receptor PD-1 (also named CD279) was discovered in 1992 (129) and is mainly expressed on activated $\mathrm{CD}^{+} \mathrm{T}$ cells and $\mathrm{CD}^{+} \mathrm{T}$ cells as well as on $\mathrm{B}$ cells in the periphery. Just like CTLA-4, as a member of CD28 family, PD-1 delivers a negative signal when interacting with its ligands (i.e., PD-L1 and PDL2). PD-1 has been an paramount target of immunotherapy now used in the clinic, though a large subset of patients fail to respond to anti PD-1 immunotherapy. The relationship between PD-1 and Tregs is just kicking off. Woods et al. found that NED (patients with no evidence of disease) displayed increased percentages of Tregs postnivolumab (anti-PD1, Bristol Myers Squibb) while relapsing patients did not (130). They concluded PD-1 blockade increased pSTAT3 (phospho-signal transducer and activator of transcription 3) expression and subsequently enchanced Tregs percentages via enhancing IL-10 production (130). Another recent study by $\mathrm{Ha}$ et al. also proved PD- $1^{+}$Tregs are characterized with stronger suppression function during chronic viral infection (131). In synergy with TGF- $\beta$, PD- 1 downregulates the threshold of TGF$\beta$-mediated signals and thereby induces the cytodifferentiation of naive T cells toward iTreg cells (132). Then, PD-L1 restrains effector $\mathrm{T}$ cell responses by enhancing the proportion of iTregs (132). Furthermore, a recent study by Overacre-Delgoffe et al. have revealed another underlying relationship between PD-1 and Tregs. They demonstrated IFN- $\gamma$-induced Treg fragility is required for an effective response to $\mathrm{PD}$-1-targeted immunotherapy (63). This study partly answers the key issue why some patients are featured with mute responsiveness to PD-1 blockade. 


\section{TIGIT, LAG-3, Tim-3}

Only a few subsets of cancer patients benefit from anti-PD- 1 and anti-CTLA- 4 therapy and these targeted medicines may induce unavoidable side effects. This imperfection has leaded deep interest in targeting of other immune checkpoint receptors.

T-cell immunoglobulin (Tim) and immunoreceptor tyrosinebased inhibitory motif domain (also termed as WUCAM, Vstm3, VSIG9), a recently defined new immune checkpoint, was first identified as another member of CD28 family. Its expression is limited to lymphocytes, especially high-level expression on regulatory T cells and NK cells (133). TIGIT binds two ligands, CD112 and CD155, which are expressed on APCs, T cells, and tumor cells, etc. To test how TIGIT play a function role in Tregs, Joller et al. (134) first identified not only is TIGIT majorly expressed on natural Tregs but also can promote induced Tregs differentiation. Intriguingly, TIGIT marks a functionally distinct subset of human nTregs with superior suppressive activity in vitro (134). The inhibitory assay result revealed that TIGIT $^{+}$Tregs inhibit cell differentiation and responses of Th1 and Th17 subsets but promote Th2 immunity through a fibrinogen-like 2-dependent mechanism (134). In addition, as a potent immunosuppressive molecule, TIGIT penetrate through early, middle, and late stages of the cancer immunity cycle (135). Besides, CD155 and CD112, ligands of TIGIT, are highly expressed on various human tumors besides immune cells (136), which indirectly suggest the involvement of TIGIT in tumor immunity. Taking into account the crucial roles of TIGIT in immunosuppression, and benefits from TIGIT blocking in animal studies or in vitro experiments, TIGIT blockade alone or together with other coinhibitory molecules would be considered as a potential therapeutic strategy for tumor management.

Lymphocyte activation gene-3 (CD223) was discovered 25 years ago as an activation marker (137). Due to its highly homologous structure to CD4, LAG-3 also binds to MHC II molecules with a much higher affinity. LAG-3 is not expressed by quiescent $\mathrm{T}$ cells but is up-regulated several days after activation (138). In contrast to effector T cells, LAG3 is highly expressed on $\mathrm{CD}^{+} \mathrm{T}$ cells that have regulatory functions, including activated natural Tregs, induced Tregs and type 1 regulatory $(\operatorname{Tr} 1) \mathrm{T}$ cells (139). Micro-scaled functional assays showed binding of LAG-3 to MHC II molecules induce an immunoreceptor tyrosine-based activation motif-mediated inhibitory signaling pathway (140). LAG-3 seems essential for maximal Tregs suppression since blockade of LAG-3 on Tregs abrogates their suppressor function (141). But the concrete role of LAG-3 for Treg-mediated suppression remains controversial. Some immunologists speculated maybe LAG-3 was essential for Treg-mediated suppressive activity at high effector $\mathrm{T} /$ Treg ratios but being dispensable at lower ratios (142). With regards to Tr1 cells, LAG-3 acts in Tr1 induction and its function indispensably since it is further expressed on $\operatorname{Tr} 1$ cells. In addition, coexpression of CD49b and LAG-3 can be utilized to authenticate $\operatorname{Tr} 1$ cell lineage in human and mice, solving the ambiguous problem of $\operatorname{Tr} 1$ cells identification in a large extent (143). However, opponents argued that inhibitory receptors cannot be supposed to ideal surface marker for Tr1 cells due to their dynamic expression (144). Anyway, the application of LAG-3 in clinical practice seems inexorable. Presently, LAG-3 has been shown to be an important immune regulator in autoimmunity (145), chronic viral infection (146), parasitic infection (147), and cancer (148). Specially, in the setting of advanced cancer, LAG-3 is preferentially expressed on tumor-infiltrating Tregs (149) and these Tregs display a terminal effector phenotype and proliferate less than LAG3- Tregs (150). LAG3-specific monoclonal antibody and LAG-Ig (IMP321) are in early phase clinical trials for cancer, these trials are still recruiting patients and thus it will be some time before trial data are available (151). It is noteworthy that human Tregs can acquire MHC II molecules via trogocytosis (152) and human $\mathrm{MHC} \mathrm{II}^{+}$Tregs had been proved more suppressive than $\mathrm{MHC}^{-} \mathrm{II}^{-}$Tregs (153). Considering inextricable relationship between MHC II and LAG-3, we can presume LAG-3 engagement escort stronger suppressive activity of MHC II ${ }^{+}$Tregs. Considering the potential role of MHC II on Tregs in mediating immune inhibition through LAG-3, interfering with the LAG-3/MHC class II pathway may help to prime or potentiate preexisting $\mathrm{T}$ cell responses to tumor antigens. Results of preclinical models also strengthened the rationale to further study of LAG-3.

T-cell immunoglobulin-3 (CD366) was identified in 2002 and alongside TIGIT, LAG-3 represent the next generation of immune checkpoints in cancer immunotherapy. Tim has been defined as a negative regulatory molecule and acts as an indispensable role in immune tolerance. Tim-3 is expressed by Tregs and is also found on other lymphocytes such as effector T cells, NK cells, DCs, and monocytes. Besides galectin-9, phosphatidyl serine, high mobility group protein B1, carcinoembryonic antigen cell adhesion molecule-1 was identified as another novel cell surface ligand of Tim-3 recently (154). The functional regulation of Tim-3 on regulatory $\mathrm{T}$ cells is achieved just by binding to these ligands. Specially, Tim-3 is expressed on only a few subsets of $\mathrm{CD}^{+} \mathrm{Foxp}^{+}$Tregs after TCR stimulation but the level is obviously upregulated on them at the sites of tissue inflammation (139). Intriguingly, other coinhibitory elements such as LAG-3, PD-1, and CTLA- 4 were also upregulated on TIM- $3^{+}$Tregs. More importantly, Tim $-3^{+}$Tregs show superior immuno-suppressive activity when compared to Tim- $3^{-}$Tregs. They preferentially express higher levels of known suppressive molecules including IL-10, granzymes and perforin (155). Notably, Tim-3+Tregs were reported, in particular, suppress Th17 cells while Tim-3-Tregs did not (155). In human tumor microenvironment, Tim- $3^{+}$Tregs form the predominant subpopulation throughout all phases of tumor progression (156). The presence of Tim- $3^{+}$Treg cells has been found to associate with unfavorable prognostic parameters such as nodal metastases in lung cancer, further supporting the value of Tim-3 as a prognostic indicator of disease progression (157). As mentioned above, either CTLA4 inhibitor or PD-1 inhibitors did not give rise to high response rate in the treatment of patients with some cancer types. It is quite urgent to identify other checkpoint inhibitors to be used in monotherapy or combotherapy with PD-1/PD-L1 inhibitors. In this context, Tim-3 marks highly suppressive Tregs that are present uniquely within the tumor microenvironment. Tim-3-targeted therapy alone or in combination with other checkpoint therapies are emerging as a potential treatment modality for further improvement of current immunotherapy. 


\section{CONCLUDING REMARKS}

Since their discovery as a key mediator of immunological selftolerance, considerable progress has been made in Tregs. However, the original recognition of Treg should be revised and updated since plenty of recent work subvert our previous understanding. For example, Tregs are not the most potent suppressive players in some tumor-settings $(158,159)$. In addition, an emerging body of research suggests that tissue-resident Tregs have specialized functions that are unique to the tissues they reside. It goes without saying that understanding tissue Tregs in diverse regions of the body would yield copious novel immunological principles. The identification of novel tissue-specific Tregs has highlighted their heterogeneity and complexity. We should focus on not only their specialized roles in regulating immune responses but also their tissue-specific functions. Following the updated cognition of Tregs, most of the contents in this Review were discussed in terms of small molecules or functional proteins.

Tregs are capable of suppressing not only conventional $\mathrm{T}$ cells but also B cells, NK cells, dendritic cells, and macrophages via humoral and cell-cell contact mechanisms $(1,160)$. An increasing number of molecules are proven to participate in Treg-mediated suppression process, including IL-2, CTLA-4, TGF- $\beta$, LAG3, GITR, granzyme B. Since these basic mechanisms have been studied and reviewed extensively, it is not absolutely essential to explore them here in detail. Remarkable progress has been made of late years in expounding the mechanisms that Tregs manipulate to exert suppression activity. But from conclusive, present research just got infinite nearly fact and what we have known remains in its infancy.

In the early stage, efforts focused on ways to use cytokines to manipulate the host immune response toward cancer cell recognition and eradication. Though significant advances were achieved with interleukin- 2 and interferon- $\alpha$, their applications

\section{REFERENCES}

1. Sakaguchi S, Yamaguchi T, Nomura T, Ono M. Regulatory T cells and immune tolerance. Cell (2008) 133:775-87. doi:10.1016/j.cell.2008.05.009

2. Merghoub T, Wolchok JD. Curbing Tregs' (lack of) enthusiasm. Cell (2017) 169:981-2. doi:10.1016/j.cell.2017.05.027

3. Panduro M, Benoist C, Mathis D. Tissue Tregs. Annu Rev Immunol (2016) 34:609-33. doi:10.1146/annurev-immunol-032712-095948

4. Ali N, Zirak B, Rodriguez RS, Cotsarelis G, Abbas AK, Rosenblum MD, et al. Regulatory $\mathrm{T}$ cells in skin facilitate epithelial stem cell differentiation article regulatory $\mathrm{T}$ cells in skin facilitate epithelial stem cell differentiation. Cell (2017) 169(6):1119-29.e11. doi:10.1016/j.cell.2017.05.002

5. Arpaia N, Green JA, Moltedo B, Arvey A, Hemmers S, Yuan S, et al. A distinct function of regulatory $\mathrm{T}$ cells in tissue protection. Cell (2015) 162:1078-89. doi:10.1016/j.cell.2015.08.021

6. Nishizuka Y, Sakakura T. Thymus and reproduction: sex-linked dysgenesia of the gonad after neonatal thymectomy in mice. Science (1969) 166:753-5. doi:10.1126/science.166.3906.753

7. Wang S, Xia P, Chen Y, Qu Y, Xiong Z, Ye B, et al. Regulatory innate lymphoid cells control innate intestinal inflammation. Cell (2017) 171:201-16.e18. doi:10.1016/j.cell.2017.07.027

8. Hori S. Control of regulatory T cell development by the transcription factor Foxp3. Science (2003) 299:1057-61. doi:10.1126/science.1079490

9. Gavin MA, Rasmussen JP, Fontenot JD, Vasta V, Manganiello VC, Beavo JA, et al. Foxp3-dependent programme of regulatory T-cell differentiation. Nature (2007) 445:771-5. doi:10.1038/nature05543 have not been established largely because of toxicity, the complex functionality and the difficulty mimicking human environment. Similarly, further study is required to evaluate the efficacy and safety of IL-34, IL-35, etc. treatment.

Afterward, multiple means to target intratumoral Tregs include small molecules are being conducted in early phase clinical trials, such as TRX518, anti-CCR4, OX40, and GITR. Recently, Neuropilin-1, amphiregulin, etc. constitute a more preferable approach to target Tregs without generating severe side effects.

Substantial data already exist that combinational treatments might be more beneficial than anti-CTLA-4 and anti-PD-1/ PD-L1 monotherapies. Considering the complexity of multiple immune checkpoints expression and their ligand, it seems necessary to evaluate combinatorial components within the tumor microenvironment. Presently, technologies using chimeric antigen receptor-engineered $\mathrm{T}$ cells is booming with high expectations for cancer immunotherapy, and Kymriah has been approved by FDA to treat B cell acute lymphoblastic leukemia. It also has applications for engineering antigen-specific Tregs to combat neoplastic diseases.

Tregs are attractive targets for immunotherapy, but a better understanding of population dynamics, and the diversity of subphenotypes is worthy of substantial additional investigation. Given the complexity of Treg biology in human diseases, targeting Treg immune-suppressing pathways for the prevention and/ or treatment of human diseases requires careful evaluation on the nature of immune response in human diseases. It is said "despite twists and turns on the road ahead, there are bright prospects for this cause."

\section{AUTHOR CONTRIBUTIONS}

Each author has participated sufficiently in the work to take public responsibility for appropriate portions of the content.

10. Fontenot JD, Gavin MA, Rudensky AY. Foxp3 programs the development and function of CD4+CD25+ regulatory T cells. Nat Immunol (2003) 4:330-6. doi: $10.1038 /$ ni904

11. Bennett CL, Christie J, Ramsdell F, Brunkow ME, Ferguson PJ, Whitesell L, et al. The immune dysregulation, polyendocrinopathy, enteropathy, X-linked syndrome (IPEX) is caused by mutations of FOXP3. Nat Genet (2001) 27:20-1. doi: $10.1038 / 83713$

12. Kitagawa Y, Ohkura N, Kidani Y, Vandenbon A, Hirota K, Kawakami $\mathrm{R}$, et al. Guidance of regulatory $\mathrm{T}$ cell development by Satb1-dependent super-enhancer establishment. Nat Immunol (2016) 18:173-83. doi:10.1038/ ni. 3646

13. Zhao D-M, Xue H-H. MLL4 keeps Foxp3 in the loop. Nat Immunol (2017) 18:957-8. doi:10.1038/ni.3811

14. Tone Y, Furuuchi K, Kojima Y, Tykocinski ML, Greene MI, Tone M. Smad3 and NFAT cooperate to induce Foxp3 expression through its enhancer. Nat Immunol (2008) 9:194-202. doi:10.1038/ni1549

15. Zheng Y, Josefowicz S, Chaudhry A, Peng XP, Forbush K, Rudensky AY. Role of conserved non-coding DNA elements in the Foxp3 gene in regulatory T-cell fate. Nature (2010) 463:808-12. doi:10.1038/Nature08750

16. Kim H-P, Leonard WJ. CREB/ATF-dependent T cell receptor-induced FoxP3 gene expression: a role for DNA methylation. J Exp Med (2007) 204:1543-51. doi:10.1084/jem.20070109

17. Burchill MA, Yang J, Vogtenhuber C, Blazar BR, Farrar MA. IL-2 receptor beta-dependent STAT5 activation is required for the development of Foxp3+ regulatory T cells. J Immunol (2007) 178:280-90. doi:10.4049/ jimmunol.178.1.280 
18. Kitoh A, Ono M, Naoe Y, Ohkura N, Yamaguchi T, Yaguchi H, et al. Indispensable role of the Runx1-Cbfbeta transcription complex for in vivosuppressive function of FoxP3+ regulatory T cells. Immunity (2009) 31:609-20. doi:10.1016/j.immuni.2009.09.003

19. Rudensky AY. Regulatory T cells and Foxp3. Immunol Rev (2012) 241:260-8. doi:10.1111/j.1600-065X.2011.01018.x.Regulatory

20. Lu L, Barbi J, Pan F. The regulation of immune tolerance by FOXP3. Nat Rev Immunol (2017) 17(11):703-17. doi:10.1038/nri.2017.75

21. Ohkura N, Kitagawa Y, Sakaguchi S. Development and maintenance of regulatory T cells. Immunity (2013) 38:414-23. doi:10.1016/j.immuni.2013.03.002

22. Feuerer M, Herrero L, Cipolletta D, Naaz A, Wong J, Nayer A, et al. Lean, but not obese, fat is enriched for a unique population of regulatory $\mathrm{T}$ cells that affect metabolic parameters. Nat Med (2009) 15:930-9. doi:10.1038/nm.2002

23. Cipolletta D, Feuerer M, Li A, Kamei N, Lee J, Shoelson SE, et al. PPAR- $\gamma$ is a major driver of the accumulation and phenotype of adipose tissue Treg cells. Nature (2012) 486(7404):549-53. doi:10.1038/nature11132

24. Vasanthakumar A, Moro K, Xin A, Liao Y, Gloury R, Kawamoto S, et al. The transcriptional regulators IRF4, BATF and IL-33 orchestrate development and maintenance of adipose tissue-resident regulatory T cells. Nat Immunol (2015) 16:276-85. doi:10.1038/ni.3085

25. Mor A, Planer D, Luboshits G, Afek A, Metzger S, Chajek-Shaul T, et al. Role of naturally occurring CD4+ CD25+ regulatory $\mathrm{T}$ cells in experimental atherosclerosis. Arterioscler Thromb Vasc Biol (2007) 27:893-900. doi:10.1161/ 01.ATV.0000259365.31469.89

26. Hamaguchi M, Sakaguchi S. Regulatory T cells expressing PPAR- $\gamma$ control inflammation in obesity. Cell Metab (2012) 16:4-6. doi:10.1016/j.cmet. 2012.06.007

27. Bapat SP, Myoung Suh J, Fang S, Liu S, Zhang Y, Cheng A, et al. Depletion of fat-resident Treg cells prevents age-associated insulin resistance. Nature (2015) 528(7580):137-41. doi:10.1038/nature16151

28. Burzyn D, Kuswanto W, Kolodin D, Shadrach JL, Cerletti M, Jang Y, et al. A special population of regulatory T cells potentiates muscle repair. Cell (2013) 155:1282-95. doi:10.1016/j.cell.2013.10.054

29. Kuswanto W, Burzyn D, Panduro M, Wang KK, Jang YC, Wagers AJ, et al. Poor repair of skeletal muscle in aging mice reflects a defect in local, interleukin-33-dependent accumulation of regulatory T cells. Immunity (2016) 44:355-67. doi:10.1016/j.immuni.2016.01.009

30. Kuhn KA, Stappenbeck TS. Peripheral education of the immune system by the colonic microbiota. Semin Immunol (2013) 25:364-9. doi:10.1016/ j.smim.2013.10.002

31. Schiering C, Krausgruber T, Chomka A, Fröhlich A, Adelmann K, Wohlfert EA, et al. The alarmin IL-33 promotes regulatory T-cell function in the intestine. Nature (2014) 513:564-8. doi:10.1038/nature 13577

32. Wang Y, Su MA, Wan YY. An essential role of the transcription factor GATA-3 for the function of regulatory T cells. Immunity (2011) 35:337-48. doi:10.1016/j.immuni.2011.08.012

33. Wohlfert E, Grainger J. GATA3 controls Foxp3+ regulatory $\mathrm{T}$ cell fate during inflammation in mice. J Clin Invest (2011) 121:4503-15. doi:10.1172/ JCI57456.Accumulation

34. Bopp T, Becker C, Klein M, Klein-Hessling S, Palmetshofer A, Serfling E, et al. Cyclic adenosine monophosphate is a key component of regulatory T cellmediated suppression. JExp Med (2007) 204:1303-10. doi:10.1084/ jem.20062129

35. Deaglio S, Dwyer KM, Gao W, Friedman D, Usheva A, Erat A, et al. Adenosine generation catalyzed by CD39 and CD73 expressed on regulatory $\mathrm{T}$ cells mediates immune suppression. J Exp Med (2007) 204:1257-65. doi:10.1084/ jem.20062512

36. Allard D, Turcotte M, Stagg J. Targeting A2 adenosine receptors in cancer. Immunol Cell Biol (2017) 95:333-9. doi:10.1038/icb.2017.8

37. Martin CA, Homaidan FR, Palaia T, Burakoff R, el-Sabban ME. Gap junctional communication between murine macrophages and intestinal epithelial cell lines. Cell Adhes Commun (1998) 5:437-49. doi:10.3109/ 15419069809005602

38. Fonseca PC, Nihei OK, Savino W, Spray DC, Alves LA. Flow cytometry analysis of gap junction-mediated Cel-Cell communication: advantages and pitfalls. Cytom A (2006) 69:487-93. doi:10.1002/cyto.20255

39. Huang B, Zhao J, Lei Z, Shen S, Li D, Shen G-X, et al. miR-142-3p restricts cAMP production in CD4+CD25- T cells and CD4+CD25+ TREG cells by targeting AC9 mRNA. EMBO Rep (2009) 10:180-5. doi:10.1038/embor.2008.224
40. Kuczma M, Wang CY, Ignatowicz L, Gourdie R, Kraj P. Altered connexin 43 expression underlies age-dependent decrease of regulatory $\mathrm{T}$ cell suppressor function in nonobese diabetic mice. JImmunol (2015) 194:5261-71. doi:10.4049/jimmunol.1400887

41. Rhett JM, Jourdan J, Gourdie RG. Connexin 43 connexon to gap junction transition is regulated by zonula occludens-1. Mol Biol Cell (2011) 22:1516-28. doi:10.1091/mbc.E10-06-0548

42. Idzko M, Ferrari D, Eltzschig HK. Nucleotide signalling during inflammation. Nature (2014) 509:310-7. doi:10.1038/nature13085

43. Klein M, Bopp T. Cyclic AMP represents a crucial component of treg cellmediated immune regulation. Front Immunol (2016) 7:1-5. doi:10.3389/ fimmu.2016.00315

44. Frenguelli BG, Wigmore G, Llaudet E, Dale N. Temporal and mechanistic dissociation of ATP and adenosine release during ischaemia in the mammalian hippocampus. J Neurochem (2007) 101:1400-13. doi:10.1111/j.14714159.2006.04425.x

45. Schwartz RH. T cell anergy. Annu Rev Immunol (2003) 21:305-34. doi:10.1146/ annurev.immunol.21.120601.141110

46. Buck MD, Sowell RT, Kaech SM, Pearce EL. Metabolic instruction of immunity. Cell (2017) 169:570-86. doi:10.1016/j.cell.2017.04.004

47. Elkord E, Abd Al Samid M, Chaudhary B. Helios, and not FoxP3, is the marker of activated Tregs expressing GARP/LAP. Oncotarget (2015) 6:20026-36. doi:10.18632/oncotarget.4771

48. Sun L, Jin H, Li H, Sun L, Jin H, Li H. GARP: a surface molecule of regulatory $\mathrm{T}$ cells that is involved in the regulatory function and TGF- $\beta$ releasing. Oncotarget (2016) 7:42826-36. doi:10.18632/oncotarget.8753

49. Zhang D, Chia C, Jiao X, Jin W, Kasagi S, Wu R, et al. D-mannose induces regulatory T cells and suppresses immunopathology. Nat Med (2017) 23(9): 1036-45. doi:10.1038/nm.4375

50. Konkel JE, Zhang D, Zanvit P, Chia C, Zangarle-Murray T, Jin W, et al. Transforming growth factor- $\beta$ signaling in regulatory $\mathrm{T}$ cells controls $\mathrm{T}$ helper-17 cells and tissue-specific immune responses. Immunity (2017) 46:660-74. doi:10.1016/j.immuni.2017.03.015

51. Piccirillo CA, Letterio JJ, Thornton AM, McHugh RS, Mamura M, Mizuhara H, et al. CD4+CD25+ regulatory $\mathrm{T}$ cells can mediate suppressor function in the absence of transforming growth factor $\beta 1$ production and responsiveness. J Exp Med (2002) 196:237-45. doi:10.1084/jem.20020590

52. Hinck AP, Mueller TD, Springer TA. Structural biology and evolution of the TGF- $\beta$ family. Cold Spring Harb Perspect Biol (2016) 8:1-52. doi:10.1101/ cshperspect.a022103

53. Stockis J, Fink W, Francois V, Connerotte T, de Smet C, Knoops L, et al. Comparison of stable human Treg and Th clones by transcriptional profiling. Eur J Immunol (2009) 39:869-82. doi:10.1002/eji.200838807

54. Levings MK, Sangregorio R, Sartirana C, Moschin AL, Battaglia M, Orban PC, et al. Human CD25+CD4+ T suppressor cell clones produce transforming growth factor, but not interleukin 10, and are distinct from type $1 \mathrm{~T}$ regulatory cells. J Exp Med (2002) 196:1335-46. doi:10.1084/jem.20021139

55. Tran DQ, Andersson J, Wang R, Ramsey H, Unutmaz D, Shevach EM. GARP (LRRC32) is essential for the surface expression of latent TGF- on platelets and activated FOXP3+ regulatory T cells. Proc Natl Acad Sci U S A (2009) 106:13445-50. doi:10.1073/pnas.0901944106

56. Wang R, Kozhaya L, Mercer F, Khaitan A, Fujii H, Unutmaz D. Expression of GARP selectively identifies activated human FOXP3+ regulatory T cells. Proc Natl Acad Sci U S A (2009) 106:13439-44. doi:10.1073/pnas.0901965106

57. Shi M, Zhu J, Wang R, Chen X, Mi L, Walz T, et al. Latent TGF- $\beta$ structure and activation. Nature (2011) 474:343-9. doi:10.1038/nature10152

58. Chen W, Jin W, Hardegen N, Lei K, Li L, Marinos N, et al. Conversion of peripheral CD4+ CD25- naive T cells to CD4+ CD25+ regulatory T cells by TGF- $\beta$ induction of transcription factor Foxp3. J Exp Med (2003) 198:1875-86. doi:10.1084/jem.20030152

59. Davidson TS, DiPaolo RJ, Andersson J, Shevach EM. Cutting edge: IL-2 is essential for TGF-beta-mediated induction of Foxp3 $\mathrm{T}$ regulatory cells. J Immunol (2007) 178:4022-6. doi:10.4049/jimmunol.178.7.4022

60. Bruder D, Probst-Kepper M, Westendorf AM, Geffers R, Beissert S, Loser K, et al. Neuropilin-1: a surface marker of regulatory T cells. Eur J Immunol (2004) 34:623-30. doi:10.1002/eji.200324799

61. Milpied P, Renand A, Bruneau J, Mendes-Da-Cruz DA, Jacquelin S, Asnafi V, et al. Neuropilin-1 is not a marker of human Foxp3+ Treg. Eur J Immunol (2009) 39:1466-71. doi:10.1002/eji.200839040 
62. Delgoffe GM, Woo S-R, Turnis ME, Gravano DM, Guy C, Overacre AE, et al. Stability and function of regulatory $\mathrm{T}$ cells is maintained by a neuropilin1-semaphorin-4a axis. Nature (2013) 501:252-6. doi:10.1038/nature12428

63. Overacre-Delgoffe AE, Chikina M, Dadey RE, Yano H, Brunazzi EA, Shayan G, et al. Interferon- $\gamma$ drives Treg fragility to promote anti-tumor immunity. Cell (2017) 169:1130-41.e11. doi:10.1016/j.cell.2017.05.005

64. Duhen T, Duhen R, Lanzavecchia A, Sallusto F, Campbell DJ. Functionally distinct subsets of human FOXP3 + Treg cells that phenotypically mirror effector Th cells. Blood (2012) 119:4430-40. doi:10.1182/blood-2011-11-392324

65. Levine AG, Medoza A, Hemmers S, Moltedo B, Niec RE, Schizas M, et al. Stability and function of regulatory $\mathrm{T}$ cells expressing the transcription factor T-bet. Nature (2017) 546:421-5. doi:10.1038/nature22360

66. Deligne C, Metidji A, Fridman W-H, Teillaud J-L. Anti-CD20 therapy induces a memory Th1 response through the IFN- $\gamma / \mathrm{IL}-12$ axis and prevents protumor regulatory T-cell expansion in mice. Leukemia (2014) 29(4): 947-57. doi:10.1038/leu.2014.275

67. Kammertoens T, Friese C, Arina A, Idel C, Briesemeister D, Rothe M, et al. Tumour ischaemia by interferon- $\gamma$ resembles physiological blood vessel regression. Nature (2017) 545:98-102. doi:10.1038/nature22311

68. Ramsdell F, Ziegler SF. FOXP3 and scurfy: how it all began. Nat Rev Immunol (2014) 14:343-9. doi:10.1038/nri3650

69. Bacchetta R, Barzaghi F, Roncarolo MG. From IPEX syndrome to FOXP3 mutation: a lesson on immune dysregulation. Ann N Y Acad Sci (2016). doi:10.1111/nyas.13011

70. Zuo WL, Yang J, Gomi K, Chao IW, Crystal RG, Shaykhiev R. EGFamphiregulin interplay in airway stem/progenitor cells links the pathogenesis of smoking-induced lesions in the human airway epithelium. Stem Cells (2017) 35:824-37. doi:10.1002/stem.2512

71. Dahlhoff M, Frances D, Kloepper JE, Paus R, Schäfer M, Niemann C, et al. Overexpression of epigen during embryonic development induces reversible, epidermal growth factor receptor-dependent sebaceous gland hyperplasia. Mol Cell Biol (2014) 34:3086-95. doi:10.1128/MCB.00302-14

72. Ritchlin CT, Krueger JG. New therapies for psoriasis and psoriatic arthritis. Curr Opin Rheumatol (2016) 28:204-10. doi:10.1097/BOR.0000000000000274

73. Shipman WD, Dasoveanu DC, Lu TT. Tertiary lymphoid organs in systemic autoimmune diseases: pathogenic or protective? F1000Res (2017) 6:196. doi:10.12688/f1000research.10595.1

74. Wang CQ, Huang YW, Wang SW, Huang YL, Tsai CH, Zhao YM, et al. Amphiregulin enhances VEGF-A production in human chondrosarcoma cells and promotes angiogenesis by inhibiting miR-206 via FAK/c-Src/PKC $\delta$ pathway. Cancer Lett (2017) 385:261-70. doi:10.1016/j.canlet.2016.10.010

75. Zhao W, Ding G, Wen J, Tang Q, Yong H, Zhu H, et al. Correlation between Trop2 and amphiregulin coexpression and overall survival in gastric cancer. Cancer Med (2017) 6:994-1001. doi:10.1002/cam4.1018

76. Tung S-L, Huang W-C, Hsu F-C, Yang Z-P, Jang T-H, Chang J-W, et al. miRNA-34c-5p inhibits amphiregulin-induced ovarian cancer stemness and drug resistance via downregulation of the AREG-EGFR-ERK pathway. Oncogenesis (2017) 6:e326. doi:10.1038/oncsis.2017.25

77. Lin H, Lee E, Hestir K, Leo C, Huang M, Bosch E, et al. Discovery of a cytokine and its receptor by functional screening of the extracellular proteome. Science (2008) 320:807-11. doi:10.1126/science.1154370

78. Liu H, Leo C, Chen X, Wong BR, Williams LT, Lin H, et al. The mechanism of shared but distinct CSF-1R signaling by the non-homologous cytokines IL-34 and CSF-1. Biochim Biophys Acta (2012) 1824:938-45. doi:10.1016/ j.bbapap.2012.04.012

79. Bézie S, Picarda E, Ossart J, Tesson L, Usal C, Renaudin K, et al. IL-34 is a Treg-specific cytokine and mediates transplant tolerance. J Clin Invest (2015) 125:3952-64. doi:10.1172/JCI81227

80. Eda H, Zhang J, Keith RH, Michener M, Beidler DR, Monahan JB. Macrophagecolony stimulating factor and interleukin-34 induce chemokines in human whole blood. Cytokine (2010) 52:215-20. doi:10.1016/j.cyto.2010.08.005

81. Foucher ED, Blanchard S, Preisser L, Garo E, Ifrah N, Guardiola P, et al. IL-34 induces the differentiation of human monocytes into immunosuppressive macrophages. Antagonistic Effects of GM-CSF and IFN $\gamma$. PLoS One (2013) 8:e56045. doi:10.1371/journal.pone.0056045

82. Garcia S, Hartkamp LM, Malvar-Fernandez B, van Es IE, Lin H, Wong J, et al. Colony-stimulating factor (CSF) 1 receptor blockade reduces inflammation in human and murine models of rheumatoid arthritis. Arthritis Res Ther (2015) 18:75. doi:10.1186/s13075-016-0973-6
83. Yang S, Jiang S, Wang Y, Tu S, Wang Z, Chen Z. Interleukin 34 upregulation contributes to the increment of MicroRNA 21 expression through STAT3 activation associated with disease activity in rheumatoid arthritis. J Rheumatol (2016) 43:1312-9. doi:10.3899/jrheum.151253

84. Zwicker S, Martinez GL, Bosma M, Gerling M, Clark R, Majster M, et al. Interleukin 34: a new modulator of human and experimental inflammatory bowel disease. Clin Sci (2015) 129:281-90. doi:10.1042/CS20150176

85. Rietkötter E, Bleckmann A, Bayerlová M, Menck K, Chuang H-N, Wenske B, et al. Anti-CSF-1 treatment is effective to prevent carcinoma invasion induced by monocyte-derived cells but scarcely by microglia. Oncotarget (2015) 6:15482-93. doi:10.18632/oncotarget.3855

86. Zhou SL, Hu ZQ, Zhou ZJ, Dai Z, Wang Z, Cao Y, et al. miR-28-5p-IL-34macrophage feedback loop modulates hepatocellular carcinoma metastasis. Hepatology (2016) 63:1560-75. doi:10.1002/hep.28445

87. Collison LW, Delgoffe GM, Guy CS, Vignali KM, Chaturvedi V, Fairweather $\mathrm{D}$, et al. The composition and signaling of the IL-35 receptor are unconventional. Nat Immunol (2012) 13:290-9. doi:10.1038/ni.2227

88. Collison LW, Workman CJ, Kuo TT, Boyd K, Wang Y, Vignali KM, et al. The inhibitory cytokine IL-35 contributes to regulatory T-cell function. Nature (2007) 450:566-9. doi:10.1038/nature06306

89. Collison LW, Chaturvedi V, Henderson AL, Giacomin PR, Guy C, Bankoti J, et al. IL-35-mediated induction of a potent regulatory $\mathrm{T}$ cell population. Nat Immunol (2010) 11:1093-101. doi:10.1038/ni.1952

90. Wojno EDT, Hosken N, Stumhofer JS, O'Hara AC, Mauldin E, Fang Q, et al. A role for IL-27 in limiting T regulatory cell populations. J Immunol (2011) 187:266-73. doi:10.4049/jimmunol.1004182

91. Turnis ME, Sawant DV, Szymczak-Workman AL, Andrews LP, Delgoffe GM, Yano H, et al. Interleukin-35 limits anti-tumor immunity. Immunity (2016) 44:316-29. doi:10.1016/j.immuni.2016.01.013

92. Olson BM, Jankowska-Gan E, Becker JT, Vignali DA, Burlingham WJ, McNeel DG. Human prostate tumor antigen-specific CD8+ regulatory T cells are inhibited by CTLA-4 or IL-35 blockade. J Immunol (2012) 189: 5590-601. doi:10.4049/jimmunol.1201744

93. Cekic C, Linden J. Purinergic regulation of the immune system. Nat Rev Immunol (2016) 16:177-92. doi:10.1038/nri.2016.4

94. Agarwal A, Fanelli G, Letizia M, Tung SL, Boardman D, Lechler R, et al. Regulatory $\mathrm{T}$ cell-derived exosomes: possible therapeutic and diagnostic tools in transplantation. Front Immunol (2014) 5:555. doi:10.3389/fimmu. 2014.00555

95. Gruenbacher G, Gander H, Rahm A, Idzko M, Nussbaumer O, Thurnher M. Ecto-ATPase CD39 inactivates isoprenoid-derived $\mathrm{V} \gamma 9 \mathrm{~V} \delta 2 \mathrm{~T}$ cell phosphoantigens. Cell Rep (2016) 16:444-56. doi:10.1016/j.celrep.2016. 06.009

96. Leonard JD, Gilmore DC, Dileepan T, Nawrocka WI, Chao JL, Schoenbach $\mathrm{MH}$, et al. Identification of natural regulatory $\mathrm{T}$ cell epitopes reveals convergence on a dominant autoantigen. Immunity (2017) 47:107-17. e8. doi:10.1016/j.immuni.2017.06.015

97. Sim GC, Martin-Orozco N, Jin L, Yang Y, Wu S, Washington E, et al. IL-2 therapy promotes suppressive ICOS+ Treg expansion in melanoma patients. J Clin Invest (2014) 124:99-110. doi:10.1172/JCI46266

98. Wu X-R, He X-S, Chen Y-F, Yuan R-X, Zeng Y, Lian L, et al. High expression of CD73 as a poor prognostic biomarker in human colorectal cancer. J Surg Oncol (2012) 106:130-7. doi:10.1002/jso.23056

99. Ren Z, Yuan Y, Ji T, Zhang C. CD73 as a novel marker for poor prognosis of oral squamous cell carcinoma. Oncol Lett (2016) 12:556-62. doi:10.3892/ ol.2016.4652

100. Leclerc BG, Charlebois R, Chouinard G, Allard B, Pommey S, Saad F, et al. CD73 expression is an independent prognostic factor in prostate cancer. Clin Cancer Res (2016) 22:158-66. doi:10.1158/1078-0432.CCR-15-1181

101. Turcotte M, Spring K, Pommey S, Chouinard G, Cousineau I, George J, et al. CD73 is associated with poor prognosis in high-grade serous ovarian cancer. Cancer Res (2015) 75:4494-503. doi:10.1158/0008-5472.CAN-143569

102. Ren Z-H, Lin C-Z, Cao W, Yang R, Lu W, Liu Z-Q, et al. CD73 is associated with poor prognosis in HNSCC. Oncotarget (2016) 7:61690-702. doi:10.18632/oncotarget.11435

103. Zhang B, Song B, Wang X, Chang XS, Pang T, Zhang X, et al. The expression and clinical significance of CD73 molecule in human rectal adenocarcinoma. Tumor Biol (2015) 36:5459-66. doi:10.1007/s13277-015-3212-x 
104. Piccione EC, Mikesell G, Daine-Matsuoka B, Walter K, Miller R, McCaffery I. Abstract 5577: a novel CD73-blocking antibody reduces production of immunosuppressive adenosine and restores T cell function. Cancer Res (2017) 77:5577. doi:10.1158/1538-7445.AM2017-5577

105. Allard B, Pommey S, Smyth MJ, Stagg J. Targeting CD73 enhances the antitumor activity of anti-PD-1 and anti-CTLA-4 mAbs. Clin Cancer Res (2013) 19:5626-35. doi:10.1158/1078-0432.CCR-13-0545

106. Waterhouse P, Penninger JM, Timms E, Wakeham A, Shahinian A, Lee KP, et al. Lymphoproliferative disorders with early lethality in mice deficient in Ctla-4. Science (1995) 270:985-8. doi:10.1126/science.270.5238.985

107. Fallarino F, Grohmann U, Hwang KW, Orabona C, Vacca C, Bianchi R, et al. Modulation of tryptophan catabolism by regulatory T cells. Nat Immunol (2003) 4:1206-12. doi:10.1038/ni1003

108. Qureshi OS, Zheng Y, Nakamura K, Attridge K, Manzotti C, Schmidt EM, et al. Trans-endocytosis of CD80 and CD86: a molecular basis for the cell-extrinsic function of CTLA-4. Science (2011) 332:600-3. doi:10.1126/ science. 1202947

109. Lee KM, Chuang E, Griffin M, Khattri R, Hong DK, Zhang W, et al. Molecular basis of T cell inactivation by CTLA-4. Science (1998) 282:2263-6. doi:10.1126/science.282.5397.2263

110. Schneider H, Smith X, Liu H, Bismuth G, Rudd CE. CTLA-4 disrupts ZAP70 microcluster formation with reduced T cell/APC dwell times and calcium mobilization. Eur J Immunol (2008) 38:40-7. doi:10.1002/eji.200737423

111. Hu H, Rudd CE, Schneider H. Src kinases Fyn and Lck facilitate the accumulation of phosphorylated CTLA- 4 and its association with PI- 3 kinase in intracellular compartments of T-cells. Biochem Biophys Res Commun (2001) 288:573-8. doi:10.1006/bbrc.2001.5814

112. Schneider $\mathrm{H}$, Valk E, Leung $\mathrm{R}$, Rudd CE. CTLA-4 activation of phosphatidylinositol 3-kinase (PI 3-K) and protein kinase B (PKB/AKT) sustains T-cell anergy without cell death. PLoS One (2008) 3:e3842. doi:10.1371/ journal.pone. 0003842

113. Kong K-F, Fu G, Zhang Y, Yokosuka T, Casas J, Canonigo-Balancio AJ, et al. Protein kinase C- $\eta$ controls CTLA-4-mediated regulatory T cell function. Nat Immunol (2014) 15:465-72. doi:10.1038/ni.2866

114. Schmidt EM, Wang CJ, Ryan GA, Clough LE, Qureshi OS, Goodall M, et al. Ctla- 4 controls regulatory $\mathrm{T}$ cell peripheral homeostasis and is required for suppression of pancreatic islet autoimmunity. J Immunol (2009) 182:274-82. doi:10.4049/jimmunol.182.1.274

115. Tang AL, Teijaro JR, Njau MN, Chandran SS, Azimzadeh A, Nadler SG, et al. CTLA4 expression is an indicator and regulator of steady-state CD4+FoxP3+ T cell homeostasis. JImmunol (2008) 181:1806-13. doi:10.4049/jimmunol.181.3.1806

116. Rubtsov YP, Rasmussen JP, Chi EY, Fontenot J, Castelli L, Ye X, et al. Regulatory $\mathrm{T}$ cell-derived interleukin-10 limits inflammation at environmental interfaces. Immunity (2008) 28:546-58. doi:10.1016/j.immuni.2008.02.017

117. Holt MP, Punkosdy GA, Glass DD, Shevach EM. TCR signaling and CD28/ CTLA-4 signaling cooperatively modulate T regulatory cell homeostasis. J Immunol (2017) 198(4):1503-11. doi:10.4049/jimmunol.1601670

118. Peggs KS, Quezada SA, Chambers CA, Korman AJ, Allison JP. Blockade of CTLA-4 on both effector and regulatory $\mathrm{T}$ cell compartments contributes to the antitumor activity of anti-CTLA-4 antibodies. JExp Med (2009) 206:1717-25. doi: 10.1084/jem.20082492

119. Jain N, Nguyen H, Chambers C, Kang J. Dual function of CTLA-4 in regulatory $\mathrm{T}$ cells and conventional $\mathrm{T}$ cells to prevent multiorgan autoimmunity. Proc Natl Acad Sci U S A (2010) 107:1524-8. doi:10.1073/pnas. 0910341107

120. Klocke K, Holmdahl R, Wing K. CTLA-4 expressed by FOXP3 + regulatory $\mathrm{T}$ cells prevents inflammatory tissue attack and not T-cell priming in arthritis. Immunology (2017) 152(1):125-37. doi:10.1111/imm.12754

121. Jeffery HC, Jeffery LE, Lutz P, Corrigan M, Webb GJ, Hirschfield GM, et al. Low-dose interleukin-2 promotes STAT-5 phosphorylation, Treg survival and CTLA-4-dependent function in autoimmune liver diseases. Clin Exp Immunol (2017) 188:394-411. doi:10.1111/cei.12940

122. Walker LSK. EFIS lecture: understanding the CTLA-4 checkpoint in the maintenance of immune homeostasis. Immunol Lett (2017) 184:43-50. doi:10.1016/j.imlet.2017.02.007

123. Danikowski KM, Jayaraman S, Prabhakar BS. Regulatory T cells in multiple sclerosis and myasthenia gravis. J Neuroinflammation (2017) 14:117. doi:10.1186/s12974-017-0892-8
124. Hu P, Liu Q, Deng G, Zhang J, Liang N, Xie J, et al. The prognostic value of cytotoxic T-lymphocyte antigen 4 in cancers: a systematic review and meta-analysis. Sci Rep (2017) 7:42913. doi:10.1038/srep42913

125. Eggermont AMM, Chiarion-Sileni V, Grob J-J, Dummer R, Wolchok JD, Schmidt H, et al. Prolonged survival in stage III melanoma with ipilimumab adjuvant therapy. N Engl J Med (2016) 375:1845-55. doi:10.1056/ NEJMoa1611299

126. Robert C, Schachter J, Long GV, Arance A, Grob JJ, Mortier L, et al. Pembrolizumab versus ipilimumab in advanced melanoma. N Engl J Med (2015) 372:2521-32. doi:10.1056/NEJMoa1503093

127. Postow MA, Chesney J, Pavlick AC, Robert C, Grossmann K, McDermott D, et al. Nivolumab and ipilimumab versus ipilimumab in untreated melanoma. N Engl J Med (2015) 372:2006-17. doi:10.1056/NEJMoa1414428

128. Hodi FS, Chesney J, Pavlick AC, Robert C, Grossmann KF, McDermott DF, et al. Combined nivolumab and ipilimumab versus ipilimumab alone in patients with advanced melanoma: 2-year overall survival outcomes in a multicentre, randomised, controlled, phase 2 trial. Lancet Oncol (2016) 17:1558-68. doi:10.1016/S1470-2045(16)30366-7

129. Ishida Y, Agata Y, Shibahara K, Honjo T. Induced expression of PD-1, a novel member of the immunoglobulin gene superfamily, upon programmed cell death. EMBO J (1992) 11:3887-95.

130. Woods DM, Ramakrishnan R, Sodré AL, Berglund A, Weber J. PD-1 blockade induces phosphorylated STAT3 and results in an increase of Tregs with reduced suppressive function. J Immunol (2017) 198:56.7.

131. Ha S-J, Park HJ, Park JS, Jeong YH, Son J, Ban YH, et al. Role of PD-1 in regulatory T cells during chronic virus infection. J Immunol (2016) 196:79.1.

132. Francisco LM, Salinas VH, Brown KE, Vanguri VK, Freeman GJ, Kuchroo VK, et al. PD-L1 regulates the development, maintenance, and function of induced regulatory T cells. J Exp Med (2009) 206:3015-29. doi:10.1084/jem.20090847

133. Lozano E, Dominguez-Villar M, Kuchroo V, Hafler DA. The TIGIT/CD226 axis regulates human $\mathrm{T}$ cell function. JImmunol (2012) 188:3869-75. doi:10.4049/jimmunol.1103627

134. Joller N, Lozano E, Burkett PR, Patel B, Xiao S, Zhu C, et al. Treg cells expressing the coinhibitory molecule TIGIT selectively inhibit proinflammatory Th1 and Th17 cell responses. Immunity (2014) 40:569-81. doi:10.1016/ j.immuni.2014.02.012

135. Manieri NA, Chiang EY, Grogan JL. TIGIT: a key inhibitor of the cancer immunity cycle. Trends Immunol (2017) 38:20-8. doi:10.1016/j.it.2016. 10.002

136. Kurtulus S, Sakuishi K, Ngiow SF, Joller N, Tan DJ, Teng MWL, et al. TIGIT predominantly regulates the immune response via regulatory $\mathrm{T}$ cells. J Clin Invest (2015) 125:4053-62. doi:10.1172/JCI81187

137. Triebel F, Jitsukawa S, Baixeras E, Roman-Roman S, Genevee C, ViegasPequignot E, et al. LAG-3, a novel lymphocyte activation gene closely related to CD4. J Exp Med (1990) 171:1393-405. doi:10.1101/cshperspect. a028597

138. Sierro S, Romero P, Speiser DE. The CD4-like molecule LAG-3, biology and therapeutic applications. Expert Opin Ther Targets (2011) 15:91-101. doi:10.1517/14712598.2011.540563

139. Anderson AC, Joller N, Kuchroo VK. Lag-3, Tim-3, and TIGIT: co-inhibitory receptors with specialized functions in immune regulation. Immunity (2016) 44:989-1004. doi:10.1016/j.immuni.2016.05.001

140. Liang B, Workman C, Lee J, Chew C, Dale BM, Colonna L, et al. Regulatory $\mathrm{T}$ cells inhibit dendritic cells by lymphocyte activation gene- 3 engagement of MHC class II. J Immunol (2008) 180:5916-26. doi:10.4049/jimmunol. 180.9.5916

141. Huang CT, Workman CJ, Flies D, Pan X, Marson AL, Zhou G, et al. Role of LAG-3 in regulatory T cells. Immunity (2004) 21:503-13. doi:10.1016/ j.immuni.2004.08.010

142. Le Mercier I, Lines JL, Noelle RJ. Beyond CTLA-4 and PD-1, the generation Z of negative checkpoint regulators. Front Immunol (2015) 6:1-15. doi:10.3389/ fimmu.2015.00418

143. Gagliani N, Magnani CF, Huber S, Gianolini ME, Pala M, Licona-Limon $\mathrm{P}$, et al. Coexpression of CD49b and LAG-3 identifies human and mouse T regulatory type 1 cells. Nat Med (2013) 19:739-46. doi:10.1038/nm.3179

144. White AM, Wraith DC. Tr1-like T cells - an enigmatic regulatory T cell lineage. Front Immunol (2016) 7:355. doi:10.3389/fimmu.2016.00355 
145. Kadowaki A, Miyake S, Saga R, Chiba A, Mochizuki H, Yamamura T. Gut environment-induced intraepithelial autoreactive CD4(+) T cells suppress central nervous system autoimmunity via LAG-3. Nat Commun (2016) 7:1-16. doi:10.1038/ncomms11639

146. Fromentin R, Bakeman W, Lawani MB, Khoury G, Hartogensis W, DaFonseca S, et al. CD4+ T cells expressing PD-1, TIGIT and LAG-3 contribute to HIV persistence during ART. PLoS Pathog (2016) 12:e1005761. doi:10.1371/journal.ppat.1005761

147. Butler NS, Moebius J, Pewe LL, Traore B, Doumbo OK, Tygrett LT, et al. Therapeutic blockade of PD-L1 and LAG-3 rapidly clears established blood-stage Plasmodium infection. Nat Immunol (2012) 13:188-95. doi:10.1038/ni.2180

148. Chen J, Chen $\mathrm{Z}$. The effect of immune microenvironment on the progression and prognosis of colorectal cancer. Med Oncol (2014) 31:82. doi:10.1007/ s12032-014-0082-9

149. Wei T, Zhang J, Qin Y, Wu Y, Zhu L, Lu L, et al. Increased expression of immunosuppressive molecules on intratumoral and circulating regulatory T cells in non-small-cell lung cancer patients. Am J Cancer Res (2015) 5:2190-201.

150. Camisaschi C, Casati C, Rini F, Perego M, De Filippo A, Triebel F, et al. LAG-3 expression defines a subset of CD4+CD25highFoxp3+ regulatory $\mathrm{T}$ cells that are expanded at tumor sites. J Immunol (2010) 184:6545-51. doi:10.4049/jimmunol.0903879

151. Andrews LP, Marciscano AE, Drake CG, Vignali DAA. LAG3 (CD223) as a cancer immunotherapy target. Immunol Rev (2017) 276:80-96. doi:10.1111/ imr.12519

152. Sega EI, Leveson-Gower DB, Florek M, Schneidawind D, Luong RH, Negrin RS. Role of lymphocyte activation gene-3 (Lag-3) in conventional and regulatory $\mathrm{T}$ cell function in allogeneic transplantation. PLoS One (2014) 9:1-12. doi:10.1371/journal.pone.0086551

153. Baecher-Allan C, Wolf E, Hafler DA. MHC class II expression identifies functionally distinct human regulatory T cells. J Immunol (2006) 176:4622-31. doi:10.4049/jimmunol.176.8.4622
154. Huang Y-H, Zhu C, Kondo Y, Anderson AC, Gandhi A, Russell A, et al. Corrigendum: CEACAM1 regulates TIM-3-mediated tolerance and exhaustion. Nature (2016) 536:359. doi:10.1038/nature13848

155. Gautron A-S, Dominguez-Villar M, de Marcken M, Hafler DA. Enhanced suppressor function of TIM-3+ FoxP3+ regulatory T cells. Eur J Immunol (2014) 44:2703-11. doi:10.1002/eji.201344392

156. Sakuishi K, Ngiow SF, Sullivan JM, Teng MWL, Kuchroo VK, Smyth MJ, et al. TIM3+FOXP3+ regulatory $\mathrm{T}$ cells are tissue-specific promoters of T-cell dysfunction in cancer. Oncoimmunology (2013) 2:e23849. doi:10.4161/ onci.23849

157. Gao X, Zhu Y, Li G, Huang H, Zhang G, Wang F, et al. TIM-3 expression characterizes regulatory $\mathrm{T}$ cells in tumor tissues and is associated with lung cancer progression. PLoS One (2012) 7:1-8. doi:10.1371/journal.pone.0030676

158. Hu G, Wu P, Cheng P, Zhang Z, Wang Z, Yu X, et al. Tumor-infiltrating CD39+ $\gamma \delta$ Tregs are novel immunosuppressive $\mathrm{T}$ cells in human colorectal cancer. Oncoimmunology (2017) 6:e1277305. doi:10.1080/2162402X.2016.1277305

159. Peng G, Wang HY, Peng W, Kiniwa Y, Seo KH, Wang R-F. Tumor-infiltrating gammadelta $\mathrm{T}$ cells suppress $\mathrm{T}$ and dendritic cell function via mechanisms controlled by a unique toll-like receptor signaling pathway. Immunity (2007) 27:334-48. doi:10.1016/j.immuni.2007.05.020

160. Tanaka A, Sakaguchi S. Regulatory T cells in cancer immunotherapy. Cell Res (2017) 27:109-18. doi:10.1038/cr.2016.151

Conflict of Interest Statement: The authors are not aware of any affiliations, memberships, funding, or financial holdings that might be perceived as affecting the objectivity of this review.

Copyright (c) 2017 Zhao, Liao and Kang. This is an open-access article distributed under the terms of the Creative Commons Attribution License (CC BY). The use, distribution or reproduction in other forums is permitted, provided the original author(s) or licensor are credited and that the original publication in this journal is cited, in accordance with accepted academic practice. No use, distribution or reproduction is permitted which does not comply with these terms. 